\title{
RENTABILIDADE DA PRODUÇÃO DE CANA-DE-AÇÚCAR SOB DOIS TIPOS DE CONTRATO DE VENDA
}

MICHELETTI, Renan Nori ${ }^{1}$ ZERA, Fabricio Simone ${ }^{1}$

GARCIA, João Rafael Medeiros AMARAL, Narayana Cavichiolli do

RESUMO: O estudo foi desenvolvido através da avaliação do fornecimento da produção de cana-de-açúcar entregue a unidade receptora. Foram levantados, os custos de implantação, tratos culturais, corte, carregamento e transporte, e posteriormente calculados os valores de fundação de cada ano de corte (depreciação), além da depreciação das máquinas; assim chegando aos custos de produção da matéria prima. Através dos dados de produtividade obtidos segundo as notas de pagamento que a usina disponibiliza aos produtores, pôde-se observar o desempenho de cada corte e as variáveis que influenciaram no aumento ou diminuição da renda do produtor. O rendimento obtido nos 8 anos de produção da cana de açúcar foram comparados, a um suposto arrendamento da mesma área. Segundo análise dos dados de produtividade e custos de implantação da cultura, permitiu-se observar altos custos de CCT cobrados ao produtor, e o corte antecipado da matéria-prima diminuindo a quantidade de açúcar total recuperável por toneladas. Chegando-se a conclusão de que o arrendamento seria a forma mais apropriada de contrato para o produtor.

Palavras-chave: Custos. Produtividade. Rendimento.

SUMMARY: This study was developed through the valuation of output of cane. Were raised, deployment costs, cultural treatments, cutting loading and carriage, and calculated the values of the foundation of each crop year (depreciation), in addition to the depreciation of machinery; so coming to the manufacturing costs of raw materials. Through the productivity data obtained in accordance with the payment notes that the power plant provides producers, possible to observe the performance of each cut and the variables that have influenced the increase or the producer's income. The income earned in the 8 years of production of sugar cane were compared, an alleged lease in the same area. According to data analysis of productivity and costs of establishments of culture, allowed themselves to observe high costs of CCT charged to the producer, and the incisionraw materia advance by decreasing the amount of ATR by tones. Arriving at the conclusion that the lease would be the most appropriate way to contract for the producer.

Keywords: Costs. Productivity. Income.

\section{INTRODUÇÃO}

O etanol motivou a expansão da cultura da cana-de-açúcar (Saccharum spp.) no Brasil passando a alavancar o dinamismo e a competitividade do setor canavieiro, expandindo assim as áreas de plantio, e consequentemente a produção e a manipulação da matéria-prima (MIGUEL, 2009). Essa expansão devese muito em função da valorização do etanol, considerado o mais importante dos combustíveis alternativos, tanto do ponto de vista econômico, como ambiental. Alem do Brasil possuir boas condições em relação aos demais países em termos de tecnologia, disponibilidade de recursos naturais, clima e solo para o cultivo da cana, a matéria-prima utilizada na fabricação de etanol e açúcar e excelente. Produzimos etanol pela metade do custo do que é obtido de milho nos Estados Unidos e um terço do mesmo produto de beterraba produzido na Europa (GOES, 2011). 
Devido à necessidade de sua expansão as agroindústrias canavieiras necessitavam expandir suas áreas de plantio para atender a demanda de produção, tanto de açúcar como de álcool. A partir de então, houve a necessidade de criar parcerias e contratos como uma alternativa para essa expansão, o que favoreceu uma grande oportunidade aos produtores agrícolas dessas regiões. O pagamento da matériaprima com a modernização das unidades agrícolas passou a ser pela qualidade da cana-de-açúcar (teor de sacarose) e não mais somente pelo seu peso (SACHS, 2007).

Segundo Fernandes et al (2007), atualmente há dois modelos de contrato de compra e venda de cana-de-açúcar, praticados pelas usinas: o contrato de fornecimento e o de arrendamento. No contrato de fornecimento o produtor fornece a cana durante período firmado no contrato, ficando responsável por todos os custos incorridos, recebendo uma renda fixa anual. Já no contrato de arrendamento, firma-se um termo onde o produtor aluga suas terras por tempo determinado para a usina. Ficando a cargo da processadora todos os custos de produção, e o pagamento é realizado com uma parcela da produção préestabelecida no contrato.

No agronegócio brasileiro, o complexo sucroalcooleiro ocupa lugar de destaque produzindo açúcar, álcool entre outros produtos de relevância para a economia nacional. O Brasil é o maior produtor de cana-de-açúcar do mundo. De acordo com o terceiro levantamento de campo feito na safra de 2015/16, realizado em dezembro de 2015 pela Companhia Nacional de Abastecimento (CONAB, 2015) foi constatado que no Brasil a produção de cana-de-açúcar, para todos os usos, foi de 658,7 milhões de toneladas com um incremento de 3,80\% em relação à safra 2014/15. O incremento não será em relação a produtividade dos canaviais de São Paulo que sofre com impacto hídrico da safra passada, mas devido ao aumento de produtividade, expectativa de produção e área plantada do Centro-Sul (CONAB, 2015).

No presente estudo, objetivou-se estudar uma propriedade fornecedora de cana-de-açúcar a uma agroindústria processadora de cana-de-açúcar da região. Foram analisados os custos de produção, do plantio até o $8^{\circ}$ Corte de seu ciclo de produção, a fim de determinar o Custo Operacional Total da cultura (COT), e posteriormente a lucratividade obtida. Após os resultados analisados, estes foram comparados ao resultado de um suposto arrendamento da mesma área; levando em consideração a quantidade paga em toneladas pela Agroindústria na região.

\section{MATERIAL E MÉTODO}

O estudo foi realizado na propriedade agrícola, localizada no município de Itajú (SP). A área destinada à avaliação e desenvolvimento do trabalho foi de 22,44 hectares, onde foi realizado o estudo a partir de 2007, com o plantio da variedade de cana-de-açúcar RB855453, com espaçamento de 1,50 m. A propriedade se encontra a 25 quilômetros de distância da unidade receptora de cana-de-açúcar da região, ao qual a propriedade entrega a matéria-prima.

Foram realizados os cálculos de custo e receita para verificar a viabilidade entre os contratos de arrendamento e fornecimento. Então na área estudada analisamos as safras agrícolas de 2007/2008 (cana planta $-1^{\circ}$ corte), 2008/2009 ( $1^{\circ}$ soqueira $-2^{\circ}$ corte), 2009/2010 ( $2^{\circ}$ soqueira $-3^{\circ}$ corte), 2010/2011 ( $3^{\circ}$ soqueira $-4^{\circ}$ corte), 2011/2012 ( $4^{\circ}$ soqueira $-5^{\circ}$ corte), 2012/2013 ( $5^{\circ}$ soqueira $-6^{\circ}$ corte), 2013/2014 ( $6^{\circ}$ soqueira $-7^{\circ}$ corte) e finalmente a de $2014 / 2015\left(7^{\circ}\right.$ soqueira $-8^{\circ}$ corte).

No contrato de fornecedor a metodologia de custo utilizada foi a do Custo Operacional Total (COT) da produção, que considera Custo Operacional Efetivo (COE) mais a depreciação, onde as despesas diretas com insumos (sementes, fertilizantes, defensivos, etc.), serviços de operação (mão de obra, operação de mecanizadas e manuais) e do corte, carregamento e transporte (CCT), e despesas 
indiretas, como depreciação de máquinas (Fundação) (MATSUNAGA et al., 1976). A soma das despesas diretas denomina-se custo operacional efetivo $(\mathrm{COE})$ e, quando somadas as despesas indiretas, o resultado denomina-se custo operacional total (COT).

Depreciação é o custo necessário para substituir os bens de capital quando se tornam improdutivos pelo desgaste físico (depreciação física), ou quando perdem valor com o decorrer dos anos devido à obsolescência tecnológica. A utilização de um bem de capital ao longo do tempo anulará seu valor ou o reduzirá a um mínimo. No atual estudo substituímos o termo Depreciação por Fundação, de acordo com o Agrianual, onde se determinou que a fundação é $27 \%$ do COT .

No custo de produção já estão embutidos os valores de depreciação da cultura em 8 anos na forma de fundação; que representam uma parcela do lucro que o produtor deve guardar para que quando for necessário renovar o canavial este tenha dinheiro para isso.

No cálculo de custo de implantação da cultura da cana-de-açúcar (Plantio), tomou-se como base a tabela 1, de custo operacional fornecida pelo anuário da agricultura brasileira, do ano referencia de 2007 (AGRIANUAL, 2007), ano de implementação da lavoura.

Os custos foram obtidos com base nos seguintes itens: quantidade de hora-máquina (HM) trabalhada, número de quilômetros rodados $(\mathrm{KM})$ para o caminhão que transportou as mudas até a propriedade, número de homens por dia trabalhado (HD), quantidade em $\mathrm{L}$ e ou $\mathrm{Kg} / \mathrm{ha}$ de produtos consumidos, corte, carregamento e transporte da cana da lavoura até a unidade de recebimento; multiplicados pelos seus respectivos preços pagos pelo produtor.

A lavoura de cana-de-açúcar após seu plantio sofreu todos os cuidados do manejo, para obter a máxima produção da área. Nas operações mecanizadas realizadas tanto no plantio como nas épocas de manejo, como pulverização com herbicidas, gradagem, subsolagem, sulcação etc., foram utilizados dois tratores, um Valtra 785 4x4 ano 2003 de $85 \mathrm{cv}$ e outro Valtra BM 110 4x4 ano 2004 de $110 \mathrm{cv}$.

O levantamento dos dados ocorreu no período de junho a julho de 2007 até 2015 e os preços dos insumos e serviços utilizados nas estimativas referem-se aos praticados no mês de cada safra. E os dados necessários para a elaboração do estudo foram obtidos por meio de análise das notas de pagamento e simples demonstrativos, disponibilizados ao produtor pela Usina para realizar os cálculos de Custo Operacional Total (COT), e os de arrendamento foram simulados no final para comparação e avaliação da viabilidade entre as duas formas de contrato com os rendimentos de produtividade e pagamento de matéria-prima.

A metodologia utilizada para os cálculos de receita baseou-se nos valores obtidos através da entrega da cana-de-açúcar, calculados segundo o modelo de pagamento através do ATR Relativo (CONSECANA, 2006) aos fornecedores. O pagamento é calculado da seguinte forma: (Toneladas) X ((ATR/pgto X (R\$) ATR/mês X 90\%) - CCT) - (Funrural).

A obtenção da tonelada de cana foi feito pelo valor da produção de cana-de-açúcar da área estudada de (22,44 ha), e o Açúcar Total Recuperável (ATR), que corresponde à quantidade de açúcar disponível na matéria-prima subtraída das perdas no processo industrial, e nos preços do açúcar e etanol vendidos pelas usinas nos mercados interno e externo.

O ATR de pagamento corresponde a quantidade de $\mathrm{Kg}$ de açúcar produzido por tonelada de cana; que será multiplicado com o valor do ATR/mês em reais referente ao mês em que a cana foi cortada, assim temos o valor a ser pago pela tonelada de cana-de-açúcar ao produtor.

O Funrural ou Contribuição Social Rural é uma contribuição social destinada a custear a seguridade (INSS) geral, segundo (CORDOVA, 2010). Este Tributo de (2,3 a 2,8\%), é cobrado sobre o resultado bruto da comercialização rural e descontado, pelo adquirente da produção, no momento da venda. 
Para a obtenção dos preços de arrendamento adotou-se; 22,70 toneladas por hectare, quantidade paga pela Usina ao produtor arrendatário. O preço da tonelada de cana foi calculado através do valor em reais do ATR referente a cada ano de corte, e multiplicado ao valor mínimo de Kg de ATR; forma pela qual o pagamento é calculado pela indústria.

E por fim calculou-se o Valor Presente Liquido (VPL) e a Taxa interna de Retorno (TIR) para verificar se a atividade é lucrativa. O VPL leva em conta o valor do dinheiro no tempo. Portanto, todas as entradas e saídas de caixa são tratadas no tempo presente. O VPL de um investimento é igual ao valor presente do fluxo de caixa líquido do projeto em análise, descontado pelo custo médio ponderado de capital. TIR é a taxa "i” que se iguala as entradas de caixa ao valor a ser investido em um projeto. Em outras palavras, é a taxa que iguala o VPL de um projeto a zero.

\section{RESULTADO E DISCUSSÃO}

Os resultados a seguir referem-se aos dados obtidos através dos custos de implantação, realização dos tratos culturais e do pagamento da cana-de-açúcar, realizado ao produtor no período de 2007, ano do plantio, até 2015 , ano do último corte $\left(8^{\circ}\right.$ Corte) pelo fornecimento da matéria-prima à unidade receptora.

O custo de implantação da área de 22,44 hectares com o plantio de cana-de-açúcar está apresentado na tabela 1, que mostra os custos operacionais totais (COT) da atividade de acordo com o AGRIANUAL (2007) na ordem de R \$ 3.321,27 por hectare, custo de implantação. Nele observamos que as despesas com os insumos são as mais onerosas ( $R$ \$) 1.695,58, seguidos pelas operações manuais ( $R$ \$) 743,40 e mecanizadas (R\$) 605,69 e administração perfazendo o custo mais baixo do plantio para um hectare de cana-de-açúcar.

TABELA 1. Estimativa do Custo Operacional Total (COT) de Implantação de 1 ha de cana-de-açúcar no ano de 2007; com base no AGRIANUAL, (2008).

(Continua)

\begin{tabular}{|c|c|c|c|c|}
\hline Descrição & Especificação & $\begin{array}{c}\text { Custo/hora } \\
(\mathbf{R} \$ / \mathbf{h})\end{array}$ & $\begin{array}{c}\text { Quantidade } \\
\text { h/há }\end{array}$ & $\begin{array}{c}\text { Custo/ha. } \\
\text { (R\$/ha) }\end{array}$ \\
\hline \multicolumn{5}{|c|}{ A-OPERAÇÕES MECANIZADAS } \\
\hline Confecção de terraços & HM Tp 110cv. & 75,39 & 0,5 & 37,70 \\
\hline Confecção de carreadores & Motoniveladora & 79,00 & 0,44 & 34,76 \\
\hline Subsolagem & HM Tp 110cv. & 57,00 & 2 & 114,00 \\
\hline Calagem ou Gesso & HM tp $85 \mathrm{cv}$. & 39,35 & 0,8 & 31,48 \\
\hline Gradagemaradora & HM Tp. $110 \mathrm{cv}$. & 93,40 & 1,3 & 121,42 \\
\hline Sulcação/adubação & HM Tp.110cv. & 57,12 & 2 & 114,24 \\
\hline Cobrição & HM Тр. 110cv. & 41,21 & 1 & 41,21 \\
\hline Subtotal A & & & & 605,69 \\
\hline \multicolumn{5}{|c|}{ B-OPERAÇÕES MANUAIS } \\
\hline Plantio & Homem-dia & 30,00 & 11,8 & 354,00 \\
\hline Combate formiga & Homem-dia & 30,00 & 0,5 & 15,00 \\
\hline Amostragem de solo & Homem-dia & 30,00 & 0,05 & 1,50 \\
\hline Carpa manual & Homem-dia & 30,00 & 11,8 & 354,00 \\
\hline Carpa química & Homem-dia & 30,00 & 0,63 & 18,90 \\
\hline Subtotal B & & & & 743,40 \\
\hline \multicolumn{5}{|l|}{ C-INSUMOS } \\
\hline Fertilizante 10.30 .20 & $\mathrm{R} \$ /$ tonelada & 803,00 & 0,6 & 481,80 \\
\hline Calcário ou Gesso & $\mathrm{R} \$ /$ tonelada & 53,00 & 1,5 & 79,50 \\
\hline Herbicidas & $\mathrm{R} \$ / \mathrm{L}$ & 37,00 & 2 & 74,00 \\
\hline
\end{tabular}


TABELA 2. Estimativa do Custo Operacional Total (COT) de Implantação de 1 ha de cana-de-açúcar no ano de 2007; com base no AGRIANUAL, (2008).

(Conclusão)

\begin{tabular}{clccc}
\hline Descrição & Especificação & $\begin{array}{c}\text { Custo/hora } \\
(\mathbf{R} \$ / \mathbf{h})\end{array}$ & $\begin{array}{c}\text { Quantidade } \\
\text { h/há }\end{array}$ & $\begin{array}{c}\text { Custo/ha. } \\
(\mathbf{R} \mathbf{\$} / \mathbf{h a})\end{array}$ \\
\hline Mudas & $\mathrm{R} \$ /$ toneladas & 62,00 & 14 & 868,00 \\
Herbicidas carpa química & $\mathrm{R} \$ / \mathrm{L}$ & 28,90 & 1,5 & 43,35 \\
Inseticida & $\mathrm{R} \$ / \mathrm{kg}$ & 595,70 & 0,25 & 148,93 \\
Subtotal C & & & & $1.695,58$ \\
\hline
\end{tabular}

\section{D-ADMINISTRAÇÃO}

\begin{tabular}{clclc}
\hline Viagens & \multirow{2}{*}{ R\$/ha } & 129,00 & 1 & 129,00 \\
$\begin{array}{c}\text { Mão de Obra Administrativa } \\
\text { Subtotal D }\end{array}$ & $\mathrm{R} \$ / \mathrm{ha}$ & 147,60 & 1 & 147,60 \\
\hline \multirow{2}{*}{ Custo Operacional Total } & \multirow{2}{*}{ (COT) } & & & 276,60 \\
\hline
\end{tabular}

Analisando esse custo de implantação da lavoura, o item Insumos, representou $51 \%$ do custo operacional total de implantação da cultura, seguido das operações manuais $22 \%$ do total, das operações mecanizadas $18 \%$ do total; e por fim o menor custo dos itens que foi de $8 \%$ do custo total, representado pelos valores de administração.

Analisando os dados do COT da atividade no decorrer do período (plantio até o $8^{\circ}$ corte), conforme a tabela 2, nota-se que dentre as operações de implantação, o alto custo das mudas que chegou a $\mathrm{R} \$ 868,00$ por hectare e o restante dos insumos foi o que mais influenciou no encarecimento do plantio da cana-de-açúcar; perfazendo $51 \%$ do Custo Operacional Total (Gráfico 1). Pode-se notar o alto valor do CCT cobrado pela indústria em todos os cortes realizados, exceto no $4^{\circ}$ corte; o que vem a influenciar na redução da renda do produtor, lembrando que distância da propriedade até a indústria é de 25 quilômetros

TABELA 3. Custo Operacional Total (COT) por ha da produção de cana-de-açúcar para os oito cortes realizados. 2016.

\begin{tabular}{|c|c|c|c|c|c|c|c|}
\hline ANO & $\begin{array}{c}\text { Custo } \\
\text { Operacional } \\
\text { Total } \\
(\mathbf{R} \$ / \mathbf{h a})\end{array}$ & $\begin{array}{c}\text { Custo } \\
\text { Operações } \\
\text { Mecanizadas } \\
(\mathbf{R} \$ / \mathbf{h a})\end{array}$ & $\begin{array}{c}\text { Custo de } \\
\text { Operações } \\
\text { Manuais } \\
\text { (R\$/ha) }\end{array}$ & $\begin{array}{l}\text { Custo de } \\
\text { Insumos } \\
\text { (R\$/ha) }\end{array}$ & $\begin{array}{c}\text { Mão de } \\
\text { Obra } \\
\text { Adm. } \\
(\mathbf{R} \$ / \text { ha) }\end{array}$ & $\begin{array}{c}\text { CCT } \\
(\mathbf{R} \$ / \mathbf{h a})\end{array}$ & $\begin{array}{c}\text { Fundação } \\
\text { (27\% COT) } \\
\text { (R\$/ha) }\end{array}$ \\
\hline $1^{\circ}$ Corte & $5.022,85$ & 209,35 & 16,87 & 820,28 & 324,6 & $2.583,9$ & 1067,85 \\
\hline $2^{\circ}$ Corte & $3.941,67$ & 205,56 & 17,3 & $\begin{array}{l}653,9 \\
\end{array}$ & 351,2 & $1.875,7$ & 837,99 \\
\hline $3^{\circ}$ Corte & $4.205,47$ & 208,55 & 18,99 & 487,48 & 385,2 & $2.211,18$ & 894,07 \\
\hline $4^{\circ}$ Corte & $2.837,81$ & 218,69 & 23,15 & 544,40 & 350,5 & $1.097,79$ & 603,31 \\
\hline $5^{\circ}$ Corte & $4.332,22$ & 236,40 & 25,0 & 671,60 & 360,0 & $2.118,20$ & 921,02 \\
\hline $6^{\circ} \mathrm{Corte}$ & $4.458,44$ & 213,70 & 25,0 & 745,65 & 360,0 & $2.166,23$ & 947,86 \\
\hline $7^{\circ}$ Corte & $3.547,15$ & 240,90 & 30,0 & 570,19 & 360,0 & $1.591,95$ & 754,11 \\
\hline $8^{\circ}$ Corte & $3.062,17$ & 1,2 & 30,0 & 0 & 360,0 & $2.019,96$ & 651,01 \\
\hline
\end{tabular}

No Gráfico 1, podemos comparar as variações ocorridas nos custos operacionais ao longo dos 8 cortes de produção do canavial. Nota-se uma significativa redução nos custos de operações manuais do $1^{\circ}$ para o $2^{\circ}$ corte; seguido das operações mecanizadas e posteriormente os insumos.

Em contra partida destaca-se em $1^{\circ}$ lugar os altos valores cobrados pelo corte carregamento e transporte (CCT) da cana-de-açúcar, que contabilizam mais da metade dos custos operacionais totais realizados na área ao longo de todo seu ciclo de produção. 
Os dados para o cálculo das receitas estão de acordo com o histórico de produtividade da área. Um aspecto positivo para o produtor; foi a média de produtividade alcançada na propriedade que ficou acima da média do estado e do país, segundo a média de produtividade do levantamento histórico da Companhia Nacional de abastecimento CONAB (2016) (Gráfico 2).

GRÁFICO 1 - Participação dos Itens no Custo Operacional Total (COT) na cultura da cana-de-açúcar nos cortes de colheita da cana. 2016.
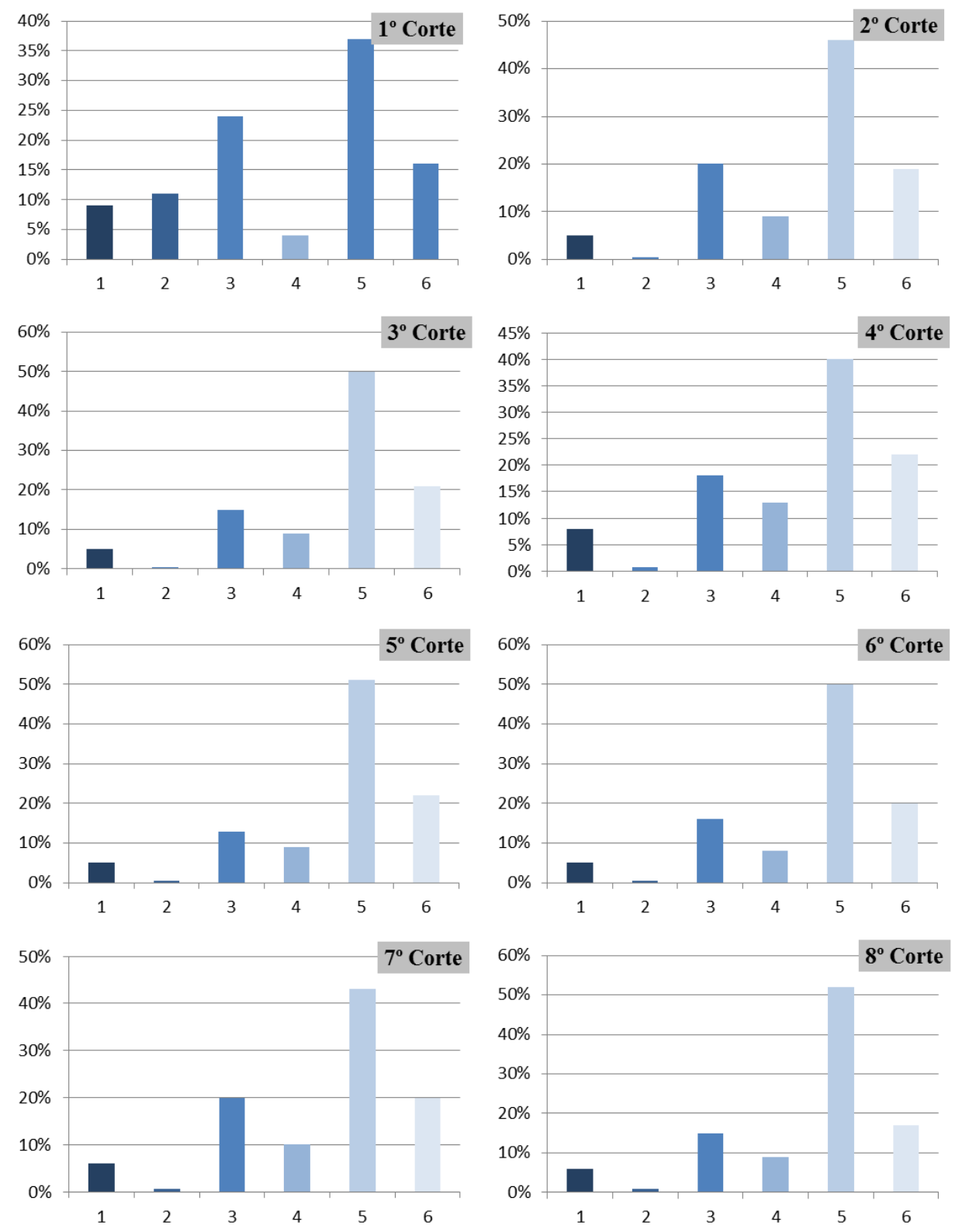

1 - CO Mecanizadas - custo de operações mecanizadas, 2 - CO Manuais - custo de operações manuais, 3 - C Insumos - custo com insumos, 4 - Mão de Obra - custo com mão de obra, 5 - CCT - corte, carregamento e transporte, 6 - Fundação.

Analisando os dados climáticos da tabela 3, podemos correlacionar os dados de produtividade da área e a influencia que as chuvas causaram no período. Com o histórico de produtividade da área (Gráfico 2), podemos notar uma queda significativa de produção do $1^{\circ}$ para o $2^{\circ}$ corte ocasionado pela grande incidência de chuva no período de Julho a Agosto de 2008; fato que forçou a realização da colheita em meio ao solo encharcado ocasionando o pisoteio e posterior falha na rebrota das soqueiras diminuindo a produtividade na safra 09/10. 
GRÁFICO 2. Produtividade de cana-de-açúcar da propriedade estudada e Média do Brasil e do Estado de São Paulo. 2016.

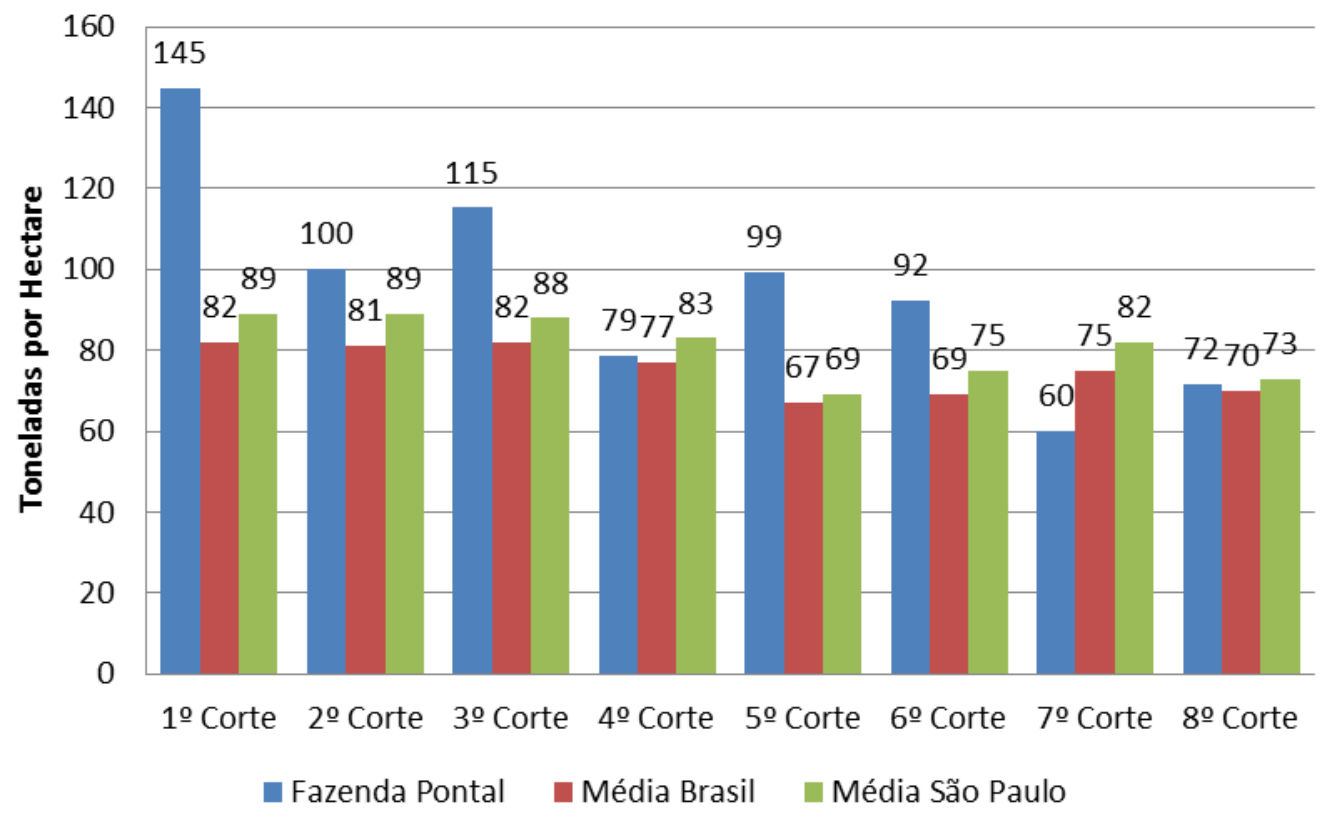

Outro fato importante relacionado as condições climáticas que podemos ressaltar no gráfico foi a queda de produtividade ocorrida no $7^{\circ}$ Corte, ocasionada por uma grande escassez de chuvas e consequentemente uma precipitação anual total muito abaixo da média no ano de 2014, (Tabela 3); acarretando em fortes dificuldades para um bom desenvolvimento da cultura devido a falta de umidade no solo.

No $1^{\circ}$ Corte, obteve-se uma produção de 3.252,76 toneladas de cana-de-açúcar numa área de 22,44 ha, assim chegando-se a uma produtividade de 144,95 toneladas por ha. O valor do ATR na safra 08/09 era de R \$ 0,2614; e a quantidade de ATR produzida pela cana foi de $136,38 \mathrm{Kg}$.

TABELA 3 - Dados climáticos da propriedade agrícola. 2016.

\begin{tabular}{|c|c|c|c|c|c|c|c|c|c|c|c|c|c|c|c|c|}
\hline & \multicolumn{2}{|c|}{2007} & \multicolumn{2}{|c|}{2008} & \multicolumn{2}{|c|}{2009} & \multicolumn{2}{|c|}{2010} & \multicolumn{2}{|c|}{2011} & \multicolumn{2}{|c|}{2012} & \multicolumn{2}{|c|}{2013} & \multicolumn{2}{|c|}{2014} \\
\hline & $\mathrm{P}$ & $\mathrm{T}$ & $\mathrm{P}$ & $\mathrm{T}$ & $\mathrm{P}$ & $\mathrm{T}$ & $\mathrm{P}$ & $\mathrm{T}$ & $\mathrm{P}$ & $\mathrm{T}$ & $\mathrm{P}$ & $\mathrm{T}$ & $\mathrm{P}$ & $\mathrm{T}$ & $\mathrm{P}$ & $\mathrm{T}$ \\
\hline Jan & 474,3 & 24,5 & 161,6 & 23,7 & 330,8 & 24 & 319,4 & 25 & 577,3 & 26,3 & 209,1 & 23,0 & 157,7 & 23,6 & 114,6 & 25,7 \\
\hline $\mathrm{Fev}$ & 207,9 & 25,5 & 284 & 24,8 & 279,1 & 25,4 & 177,8 & 25,6 & 111,8 & 26 & 125,9 & 24,5 & 80,0 & 24,4 & 26,0 & 25,4 \\
\hline Mar & 94,8 & 25,6 & 102,8 & 24,5 & 147,8 & 25,2 & 119,3 & 24,6 & 127,4 & 22,5 & 98,4 & 24,4 & 159,0 & 23,6 & 0 & 24,4 \\
\hline Abr & 51,3 & 24,9 & 121,8 & 23.1 & 35,5 & 22,8 & 86,3 & 23,3 & 65,2 & 22,8 & 64,7 & 22,3 & 73,8 & 21,3 & 0 & 24,0 \\
\hline Mai & 82,3 & 19,3 & 89,6 & 19,5 & 47,4 & 20,8 & 54 & 20,0 & 24,0 & 19,0 & 87,3 & 18,7 & 66,0 & 19,8 & 0 & 19,3 \\
\hline Jun & 1,8 & 20,9 & 57,8 & 19,0 & 25,3 & 17 & 0,9 & 19 & 39 & 16,4 & 179,5 & 17,9 & 132,8 & 18,6 & 0 & 19,4 \\
\hline Jul & 240 & 18,6 & 75,7 & 19,9 & 0 & 19,6 & 45,8 & 20,8 & 8,2 & 17,4 & 22,1 & 17,4 & 23,2 & 16,8 & 21,2 & 17,2 \\
\hline Ago & 0 & 21,4 & 112 & 22,1 & 55 & 20.22 & 0 & 20 & 20,6 & 18,6 & 0 & 18,9 & 0,6 & 18,0 & 8,4 & 19,1 \\
\hline Set & 2,6 & 24,4 & 39,2 & 21 & 137,3 & 21,6 & 105,4 & 22,8 & 10,8 & 21,9 & 46,6 & 21,3 & 38,8 & 21,0 & 16,8 & 22,0 \\
\hline Out & 50,9 & 24,3 & 159,3 & 23,5 & 102,6 & 22,5 & 74,4 & 23 & 155,2 & 22,6 & 80,2 & 23,7 & 98,4 & 21,8 & 6,6 & 23,7 \\
\hline Nov & 218,9 & 23,9 & 90,9 & 24,2 & 270,9 & 25,9 & 86,2 & 24,8 & 22,3 & 74,9 & 85,5 & 23,1 & 158,8 & 23,5 & 13,2 & 24,7 \\
\hline Dez & 240,5 & 24 & 278,8 & 30,4 & 328,9 & 24,18 & 411,7 & 25,6 & 24,4 & 148 & 136,5 & 25 & 55,4 & 24,9 & 42,6 & 24,5 \\
\hline Total & $1.665,3$ & & $1.573,5$ & & $1.760,6$ & & $1.481,2$ & & $1.186,2$ & & $1.135,8$ & & 1044,5 & & 249,4 & \\
\hline
\end{tabular}

Fonte: Centro integrado de informações agrometeorológicas - Ciiagro (http://www.ciiagro.sp.gov.br/). P precipitação total mensal, em milímetros $(\mathrm{mm})$. $\mathrm{T}$ - temperatura média mensal em graus Celsius $\left({ }^{\circ} \mathrm{C}\right)$.

Observando a tabela e segundo informações do produtor, podemos notar algumas falhas que contribuíram na redução da rentabilidade. No $1^{\circ}$ e no $4^{\circ}$ Corte, a cana-de-açúcar foi colhida antes do período de sua total maturação, devido à falta de uma melhor comunicação entre usina e fornecedor. A quantidade de Kg de ATR por tonelada de cana-de-açúcar foi reduzida, e como o lucro do produtor é em função do ATR esse tipo de falha deve ser evitado pelo fornecedor. 
Outro fator que contribuiu para o aumento das despesas, foi o alto custo do CCT descontado do valor do pagamento. Outro ponto este que o produtor fornecedor deve ficar atento e tentar uma melhor negociação com a Usina. Dependendo das condições, torna-se viável a contratação de terceiros ou até mesmo a compra de transbordos e caminhões.

Após o final da safra, no fechamento, temos o valor final do ATR. Esse valor deve ser corrigido em relação ao valor do ATR pago ao produtor na safra. A sua diferença será corrigida pela indústria no começo da safra seguinte, é o chamado reajuste. Os reajustes e complementos de safra pagos, foram somados ao valor recebido pela entrega da cana na safra seguinte.

TABELA 4 - Dados de Receita do canavial, contrato fornecedor, para pagamento da matéria prima.2016.

\begin{tabular}{|c|c|c|c|c|c|c|c|c|}
\hline Descrição & $\begin{array}{c}1^{\circ} \text { Corte } \\
2008\end{array}$ & $\begin{array}{c}2^{\circ} \text { Corte } \\
2009\end{array}$ & $\begin{array}{c}3^{\circ} \text { Corte } \\
2010\end{array}$ & $\begin{array}{c}4^{\circ} \text { Corte } \\
2011\end{array}$ & $\begin{array}{c}5^{\circ} \text { Corte } \\
2012\end{array}$ & $\begin{array}{c}6^{\circ} \text { Corte } \\
2013\end{array}$ & \begin{tabular}{|c|}
$7^{\circ}$ Corte \\
2014
\end{tabular} & $\begin{array}{c}8^{\circ} \text { Corte } \\
2015\end{array}$ \\
\hline \multicolumn{9}{|l|}{ Toneladas } \\
\hline Total & $3.252,76$ & $2.246,60$ & $2.586,50$ & $1.760,62$ & $2.227,4$ & $2.068,68$ & 1351,18 & $1.607,36$ \\
\hline Ton/ha & 144,95 & 100,12 & 115,26 & 78,56 & 99,26 & 92,19 & 60,21 & 71,63 \\
\hline ATR/pgto & 136,38 & 148,12 & 146,48 & 131,96 & 136,92 & 133,50 & 132,60 & 132,92 \\
\hline ATR/mês & 0,2614 & 0,2913 & 0,3129 & 0,5148 & 0,4922 & 0,444 & 0,4662 & 0,4737 \\
\hline Vlr bruto/ton & 35,65 & 43,14 & 45,83 & 67,93 & 67,39 & 59,27 & 61,82 & 62,96 \\
\hline CCT (23km) & 17,82 & 18,73 & 19,00 & 14,00 & 21,34 & 23,50 & 26,44 & 28,20 \\
\hline Vlr/ton & 17,83 & 24,41 & 26,83 & 53,93 & 46,05 & 35,77 & 35,38 & 34,76 \\
\hline Pagamento & $90 \%$ & $90 \%$ & $90 \%$ & $90 \%$ & $90 \%$ & $90 \%$ & $90 \%$ & $90 \%$ \\
\hline Vlr final/ton & 16,05 & 21,97 & 24,15 & 48,54 & 41,45 & 32,20 & 31,84 & 31,28 \\
\hline Total $(\mathrm{R} \$)$ & $52.197,04$ & $49.357,80$ & $69.172,32$ & $85.460,49$ & $92.318,60$ & $66.604,46$ & $43.021,00$ & $50.278,22$ \\
\hline Funrural & $3.153,82$ & $2.784,44$ & $3.961,91$ & $4.365,26$ & $4.920,39$ & $2.863,99$ & $1.849,94$ & $2.205,96$ \\
\hline Sub. Total & $49.043,22$ & $46.573,36$ & $65.210,41$ & 81.095 .23 & $87.398,21$ & $63.740,47$ & $41.172,00$ & $48.072,26$ \\
\hline Reajuste Safra & $\mathrm{X}$ & $18.052,36$ & $15.342,56$ & $15.342,56$ & $2.390,83$ & $1.809,27$ & $8.511,30$ & $11.824,81$ \\
\hline Complemento & $\mathrm{X}$ & $\mathrm{X}$ & $\mathrm{X}$ & $\mathrm{X}$ & $\mathrm{X}$ & $\mathrm{X}$ & $\mathrm{X}$ & $\mathrm{X}$ \\
\hline \multirow[t]{2}{*}{ Valor NF } & $49.043,22$ & $64.625,72$ & $80.552,97$ & $96.437,79$ & $89.789,04$ & $65.549,74$ & $49.683,3$ & $\overline{59.897,07}$ \\
\hline & & & & & & & \multicolumn{2}{|r|}{$\mathbf{5 5 . 5 7 8 , 8 5}$} \\
\hline
\end{tabular}

Fonte: Dados da propriedade agrícola

TABELA 5 - Dados de Receita do canavial, contrato de arrendamento, para pagamento de matéria-prima. 2016.

\begin{tabular}{|c|c|c|c|c|c|c|c|c|}
\hline Descrição & $\begin{array}{c}1^{\circ} \text { Corte } \\
2008 \\
\end{array}$ & $\begin{array}{c}2^{\circ} \text { Corte } \\
2009 \\
\end{array}$ & $\begin{array}{c}3^{\circ} \text { Corte } \\
2010 \\
\end{array}$ & $\begin{array}{c}4^{\circ} \text { Corte } \\
2011 \\
\end{array}$ & $\begin{array}{c}5^{\circ} \text { Corte } \\
2012 \\
\end{array}$ & $\begin{array}{c}6^{\circ} \text { Corte } \\
2013 \\
\end{array}$ & $\begin{array}{c}7^{\circ} \text { Corte } \\
2014 \\
\end{array}$ & $\begin{array}{c}8^{\circ} \text { Corte } \\
2015 \\
\end{array}$ \\
\hline Ton/ha & 22,70 & 22,70 & 22,70 & 22,70 & 22,70 & 22,70 & 22,70 & 22,70 \\
\hline ATR/pgto & 121,97 & 121,97 & 121,97 & 121,97 & 121,97 & 121,97 & 121,97 & 121,97 \\
\hline ATR/mês & 0,2614 & 0,2913 & 0,3475 & 0,5148 & 0,4922 & 0,4440 & 0,4662 & 0,4737 \\
\hline Vlr/ton & 31,88 & 35,53 & 42,38 & 62,79 & 60,03 & 54,15 & 56,86 & 57,78 \\
\hline Área (ha) & 22,44 & 22,44 & 22,44 & 22,44 & 22,44 & 22,44 & 22,44 & 22,44 \\
\hline Total $(\mathbf{R} \$)$ & $16.239,89$ & $18.098,48$ & $21.587,86$ & $31.984,47$ & $30.578,56$ & $27.608,38$ & $28.963,80$ & $29.432,44$ \\
\hline
\end{tabular}

Fonte: Dados da propriedade agrícola

Relacionando-se os custos de produção de implantação da cultura e de seus tratos culturais, com os valores recebidos pelo pagamento da matéria-prima, chegou-se a conclusão de que o produtor recuperou seus investimentos realizados no plantio a partir do $4^{\circ}$ Corte de sua produção (Tabela 6). 
TABELA 6 - Custo de produção x Preço recebido, em R\$/Área total. 2016.

\begin{tabular}{crrrr}
\hline & Custo produção & Pag. Cana & \multicolumn{1}{c}{ FCL } & \multicolumn{1}{c}{ FCA } \\
\hline Cana Planta & $74.529,30$ & $X$ & $(74.529,30)$ & $X$ \\
$1^{\circ}$ Corte & $54.730,04$ & $49.043,22$ & $(5.686,82)$ & $(80.216,12)$ \\
$2^{\circ}$ Corte & $46.360,37$ & $64.625,72$ & $18.265,35$ & $(61.950,77)$ \\
$3^{\circ}$ Corte & $44.751,87$ & $80.552,97$ & $35.801,10$ & $(26.149,67)$ \\
$4^{\circ}$ Corte & $39.046,05$ & $96.437,79$ & $57.391,74$ & $31.242,07$ \\
$5^{\circ}$ Corte & $49.682,61$ & $89.789,04$ & $40.106,43$ & $71.348,50$ \\
$6^{\circ}$ Corte & $51.437,19$ & $65.549,74$ & $14.112,55$ & $85.461,05$ \\
$7^{\circ}$ Corte & $43.874,69$ & $49.683,30$ & $5.808,61$ & $91.269,66$ \\
$8^{\circ}$ Corte & $23.387,19$ & $59.897,07$ & $36.509,88$ & $127.779,54$ \\
\hline
\end{tabular}

FCL -Fluxo de caixa líquido, FCA -Fluxo de caixa acumulado, Números entre parentes são valores negativos.

Fonte: Dados da propriedade agrícola.

Na tabela 6, os valores referentes ao custo de produção da cana planta e dos 8 cortes realizados; são obtidos através da relação dos custos com COT por ha (Tabela 1) multiplicados pela área total do canavial (22,44 ha) desconsiderando somente o valor da CCT, o qual já é descontado do valor de pagamento da matéria prima para o produtor.

No custo de produção já estão embutidos os valores de depreciação da cultura em 8 anos na forma de fundação; que representam uma parcela do lucro que o produtor deve guardar para que quando for necessário renovar o canavial este tenha dinheiro para isso.

Levando em consideração o FCA obtido através do fornecimento da matéria-prima a Usina; seu valor, foi relacionado com um suposto arrendamento da mesma área. Levando em conta a quantidade de toneladas paga por hectares pela mesma na região onde foi realizado o estudo; a fim de se chegar a qual prática melhor se adequaria a propriedade.

Para a obtenção dos preços de arrendamento adotou-se 22,70 toneladas por hectares, quantidade paga pela Usina ao produtor arrendatário. O preço da tonelada de cana foi calculado através do valor em reais do ATR referente a cada ano de corte, e multiplicado ao valor mínimo de Kg de ATR; forma pela qual o pagamento é calculado pela indústria (Tabela 5).

Neste tipo de contrato o produtor não tem nenhuma despesa em relação a custo de produção, tratos culturais, CCT e depreciação; apenas recebendo o pagamento pelo aluguel de suas terras. A margem de lucro é reduzida, pois a maior parte da produção fica com a Indústria, porém no caso da propriedade em estudo levando em conta todas as despesas, depreciação anual, falhas (relacionadas ao clima, e deslizes do produtor); a rentabilidade apresentada pelo suposto arrendamento da área mostrou ser a melhor opção (Tabela 7).

TABELA 7 - Comparação dos rendimentos das formas de contratos, fornecedor e arrendatário da propriedade em estudo. 2016.

\begin{tabular}{ccc}
\hline Descrição & Fornecedor & Arrendatário \\
\hline Custo Produção & $427.799,31$ & 0 \\
Preço Recebido & $555.578,85$ & $204.493,88$ \\
Rendimento & $127.779,54$ & $204.493,88$ \\
\hline
\end{tabular}

Fonte: Dados da propriedade agrícola.

Analisando o Valor Presente Líquido (VPL) e a Taxa Interna de Retorno (TIR) do estudo nos permitem analisar a viabilidade financeira dessa atividade, a partir do fluxos de caixa. Portanto aqui 
obtivemos um VPL de R $\$ 67.687,33$ o que indica o lucro em reais que a atividade traz, com uma TIR de taxa de juros de $22 \%$ para qual o VPL ser nulo, e quanto maior a TIR, melhor e mais lucrativa é a atividade, é como uma taxa de juros que uma aplicação financeira precisaria render para ser tão lucrativa quanto essa atividade.

Tabela 8 - Valor Presente Liquido - VPL e Taxa Interna de Retorno - TIR do presente estudo. 2016.

\begin{tabular}{crrr}
\hline \multicolumn{1}{r}{ FC } & \multicolumn{1}{l}{ VPL } & \multicolumn{1}{c}{ TIR } \\
\hline $\mathbf{0}$ & $-74.529,30$ & $\mathrm{R} \$ 67.687,33$ & $25,00 \%$ \\
$\mathbf{1}^{\mathbf{o}}$ ano & $-5.265,35$ & & \\
$\mathbf{2}^{\mathbf{o}}$ ano & $18.265,35$ & & \\
$\mathbf{3}^{\mathbf{o}}$ ano & $35.801,10$ & & \\
$\mathbf{4}^{\mathbf{o}}$ ano & $57.391,74$ & & \\
$\mathbf{5}^{\mathbf{o}}$ ano & $40.106,43$ & & \\
$\mathbf{6}^{\mathbf{o}}$ ano & $14.112,55$ & & \\
$\mathbf{7}^{\mathbf{o}}$ ano & $5.808,61$ & \multicolumn{2}{c}{ TMA } \\
$\mathbf{8}^{\mathbf{o}}$ ano & $36.509,88$ & \multicolumn{2}{c}{$10 \%$ ao ano } \\
\hline
\end{tabular}

\section{CONCLUSÃO}

Considerando-se os custos de produção, e os valores obtidos pela entrega da matéria-prima pelo produtor; comparando-se estes com o suposto arrendamento da área, podemos concluir que os resultados econômicos para o fornecimento de cana não foram satisfatórios, para a propriedade estudada no período de 2007 à 2015. O FCA (Fluxo de caixa acumulado) mostra que o produtor recuperou seu investimento a partir do $4^{\circ}$ Corte da cana, e seu lucro foi baixo. Tornando inviável o fornecimento de sua produção para a Usina. Dado ao exposto, conclui-se que o arrendamento é a forma de contrato mais rentável para a propriedade estudada no período que compreende o estudo. Para corroborar com o estudo verificou-se uma excelente viabilidade na atividade após analise do VPL e TIR.

\section{REFERÊNCIAS}

AGRIANUAL: Anuário da Agricultura Brasileira, 2008. São Paulo: FNP Consultoria \&Comércio, 2007. $260 \mathrm{p}$.

AGRIANUAL: Anuário da Agricultura Brasileira, 2009. São Paulo: FNP Consultoria \&Comércio, 2008. $254 \mathrm{p}$.

Associação dos Fornecedores de Cana de Guariba SOCICANA. ATR Relativo e a importância do ATR de Fechamento - Disponível em: $<$ http://socicana.com.br/noticias/atr-relativo-e-a-importancia-do-atr-defechamento-o-exemplo-do-sr-joao/>. Acesso em: 24 Mar .2016.

COMPANHIA NACIONAL DE ABASTECIMENTO. Acompanhamento da safra brasileira: cana-deaçúcar, Terceiro levantamento, v. 2 - Safra2015/16, n. 3 - dezembro/2015 - Companhia Nacional de Abastecimento. - Brasília : Conab 2015. 
CONSELHO DOS PRODUTORES DE CANA-DE-AÇÚCAR, AÇÚCAR E ÁLCOOL DO ESTADO DE

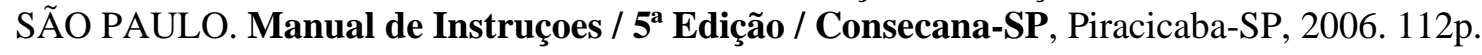

CORDOVA, A.F; O que é funrural? Disponível em: <http://www.agron.com.br/v/5744-o-que-e-ofunrural>. Acesso em 25 out. 2015.

FERNANDES, A. C. L.; BELLINGIERI, J. C. Modelos de venda de cana-de-açúcar: comparação entre contratos de fornecimento e arrendamento. Revista Epeq/Fafibe, Bebedouro, 2007.

MIGUEL, F.B. Análise de rentabilidade e risco na produção de cana-de-açúcar na região norte do Estado de São Paulo sob dois tipos de arranjos contratuais. Botucatu : [s.n.], 2009. x, $71 \mathrm{f}$.

SACHS, R.C. Remuneração da tonelada de cana-de-açúcar no Estado de São Paulo. Informações Econômicas, São Paulo, v.37, n.2, fev. 2007.

UDOP. União dos Produtores de Bioenergia. São Paulo SP, 2015. Disponível em:http://www.udop.com.br/index.php?cod=993\&item=noticias . Acesso em: 14 Set. 2015.

UNIÃO DA AGROINDUSTRIA CANAVIEIRA DO ESTADO DE SÃO PAULO. Cana-de-açúcar é carro-chefe da produção agropecuária do estado de São Paulo. São Paulo SP, 2011. Disponível em: http://www.udop.com.br/download/unica/not 2143.pdf 
